\title{
Analysis of Mechanisms Involved in the Cucumber mosaic virus Satellite RNA-mediated Transgenic Resistance in Tomato Plants
}

\author{
Fabrizio Cillo, Mariella M. Finetti-Sialer, Maria A. Papanice, and Donato Gallitelli \\ Dipartimento di Protezione delle Piante e Microbiologia Applicata, Università degli Studi and Istituto di Virologia Vegetale \\ del CNR—sezione di Bari, Via Amendola 165/A, 70126 Bari, Italy
}

Submitted 8 July 2003. Accepted 4 September 2003.

\begin{abstract}
Transgenic tomato (Lycopersicon esculentum Mill. cv. UC82) plants expressing a benign variant of Cucumber mosaic virus satellite RNA (CMV Tfn-satRNA) were generated. The transformed plants did not produce symptoms when challenged with a satRNA-free strain of CMV (CMVFL). The same plant lines initially were susceptible to necrosis elicited by a CMV strain supporting a necrogenic variant of satRNA (CMV-77), but a phenotype of total recovery from the necrosis was observed in the newly developing leaves. The features of the observed resistance were analyzed and are consistent with two different mechanisms of resistance. In transgenic plants inoculated with CMV-FL strain, the symptomless phenotype was correlated to the down-regulation of CMV by Tfn-satRNA, amplified from the transgene transcripts, as the first resistance mechanism. On the other hand, the delayed resistance to CMV-77 in transgenic tomato lines was mediated by a degradation process that targets satRNAs in a sequence-specific manner. Evidence is provided for a correlation between a reduced accumulation level of transgenic messenger TfnsatRNA, the accumulation of small (approximately 23 nucleotides) RNAs with sequence homology to satRNAs, the progressively reduced accumulation of 77-satRNA in infected tissues, and the transition in infected plants from diseased to healthy. Thus, events leading to the degradation of satRNA sequences indicate a role for RNA silencing as the second mechanism determining resistance of transgenic tomato lines.
\end{abstract}

Cucumber mosaic virus (CMV), the type species of the genus Cucumovirus in the family Bromoviridae (Roossinck et al. 1999), is a tripartite plant virus with four or five encapsidated RNAs. Some strains of CMV exhibit a supernumerary linear RNA component of 332 to 405 nucleotides (nt) that has been demonstrated to be a true satellite RNA (satRNA). This satRNA does not show any apparent homology to the viral genomic RNAs, but depends on its helper virus for replication, encapsidation, and transmission (Garcia-Arenal and Palukaitis 1999; Palukaitis et al. 1992).

In certain host plant species, CMV satRNA variants can sometimes affect CMV replication, pathogenesis, and symptom expression. The biological response of tomato (Lycopersicon esculentum Mill.) makes it possible to distinguish at least three types of satRNA variants depending on whether the disease symptoms are unaffected, intensified, or attenuated

Corresponding author: D. Gallitelli, E-mail: gallitel@agr.uniba.it
(Collmer and Howell 1992; Garcia-Arenal and Palukaitis 1999; Roossinck et al. 1992). Variants with attenuating effects (benign satRNAs) have been studied extensively as potential or actual biocontrol agents for the prevention of CMV-induced diseases of tomato (Jacquemond and Tepfer 1998; Kaper 1993; Tien and $\mathrm{Wu}$ 1991). Two main approaches to biocontrol of CMV have been suggested, and both of them have been tested in experimental or field conditions (Garcia-Arenal and Palukaitis 1999; Gallitelli 1998; Jacquemond and Tepfer 1998): i) the preinoculation of tomato seedlings with a mild strain of CMV supporting a benign variant of satRNA for the cross-protection of crops after transplanting and ii) the expression of a benign satRNA sequence in transgenic plants. Cross-protected tomato crops showed resistance against CMV strains supporting necrogenic satRNA variants (Gallitelli 1998); whereas, except in one case (Monti et al. 1999), the transgenic lines have been tested and shown to be effectively resistant only to satRNAfree CMV. However, in the exceptional case, the occurrence of mixed infections with other viruses in the open field did not permit a clear interpretation of the results. Thus, there are no data on what could be the response of a plant expressing transgenic sequences of a benign satRNA upon infection by a CMV strain supporting a necrogenic variant of satRNA. A similar situation has been reproduced by infecting untransformed tomato plants with an inoculum containing two satRNA variants (Jacquemond and Lot 1981; Smith et al. 1992). In these instances, in infections where either a necrogenic and a benign satRNA were inoculated simultaneously or the necrogenic satRNA was inoculated at a later time, the ratio of the two satRNAs that accumulated was largely in favor of the necrogenic variant, and the disease resulted in the typical lethal necrosis symptoms.

It would be difficult to predict the effectiveness of resistance toward a necrogenic satRNA of tomato plants expressing a nonnecrogenic one, unless resistance mechanisms other than the competition for replication between satRNA variants are involved. One of these possible mechanisms is RNA silencing, where viruses and viral sequences are inducers and targets of specific RNA degradation pathways, also referred to as posttranscriptional gene silencing (PTGS) or RNA-mediated resistance (Baulcombe 1996; Marathe et al. 2000). In experiments involving different virus-satRNA systems, resistance already has been associated to PTGS. Taliansky and associates (1998) obtained PTGS-mediated resistance to Groundnut rosette virus (GRV) in transgenic Nicotiana benthamiana plants expressing sequences of a mild variant of the GRV satellite RNA, whereas Wang and associates (2001) reported the induction of RNA silencing and transgenic DNA methylation when the satRNA 
of Cereal yellow dwarf virus expressed in tobacco plants was replicated to high levels by a helper virus.

Previously, we reported the molecular-biological properties of a benign CMV satRNA, denoted Tfn-satRNA, that was isolated in tomato fields in southern Italy (Crescenzi et al. 1993; Gallitelli et al. 1997; Grieco et al. 1997). Tfn-satRNA is a 390nt molecule that reduced the level of replication of CMV-Tfn (its natural helper virus) and attenuated symptoms induced in tomato by CMV-Tfn as well as by other CMV strains belonging to subgroups IA, IB, and II. Additionally, it has been shown to be a genetically stable molecule, under both laboratory and field conditions, following evolutionary dynamics different from those of the necrogenic satRNAs (Gallitelli et al. 1997; Grieco et al. 1997).

In this article, we present data on the resistance conferred by Tfn-satRNA, expressed in a transgenic tomato line, to CMV strains either supporting or not supporting a necrogenic satRNA. The features of the observed resistance were analyzed, and two mechanisms involving the down-regulation of helper virus and PTGS are discussed.

\section{RESULTS}

Genetic analysis of the transformed plant lines.

The binary expression vector pBI.TC5.16 was designed to express the CMV-Tfn-satRNA in plants, under the control of the Cauliflower mosaic virus 35S promoter and the Agrobacterium tumefaciens NOS terminator. Five tomato plants transformed with this construct were obtained. Northern blot hybridization of total RNA preparations obtained from these plants showed the presence of a satRNA-related band with electrophoretic mobility corresponding to approximately 0.7 $\mathrm{kb}$, consistent with the size of a primary mRNA transcript containing full-size Tfn-satRNA, the bordering vector sequences, and a poly(A) tail (data not shown). The integration of a single insertion was confirmed by Southern blot hybridization analysis of plant genomic DNA and by segregation tests on selective media (data not shown). The $\mathrm{T}_{2}$ progeny of the homozygous line UCTC5.9.2 was used in all the described experiments.

\section{Challenge inoculation with satRNA-free strains of CMV.}

In all, 10 plants of the line UCTC5.9.2 and 10 of the untransformed UC82 were inoculated with a purified preparation of the satRNA-free strain CMV-FL at $100 \mu \mathrm{g} / \mathrm{ml}$ or mockinoculated with buffer. The concentration of inoculum was enough to produce infection in all the challenged plants. All untransformed plants exhibited the symptoms of leaf shoestring, typically induced by CMV in tomato, by 12 days postinoculation (dpi), while both transformed and mock-inoculated plants appeared symptomless.

Northern blot hybridization of total nucleic acid extracts obtained from these plants with CMV-RNA3-specific and Tfn-

A

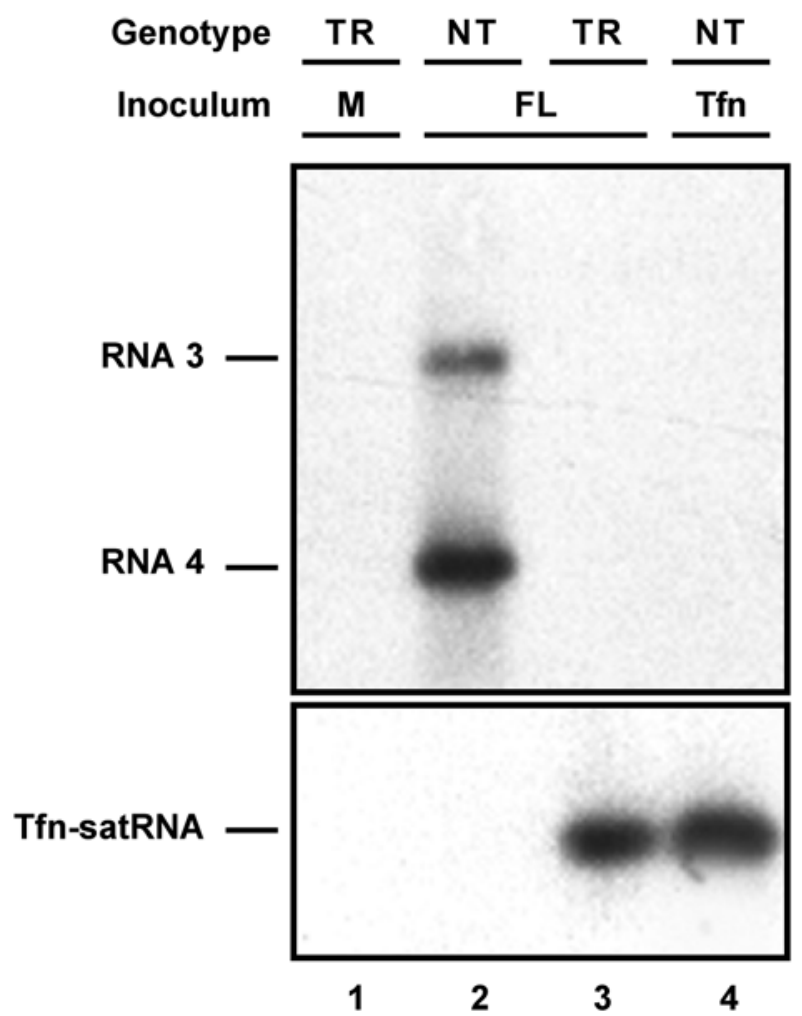

B

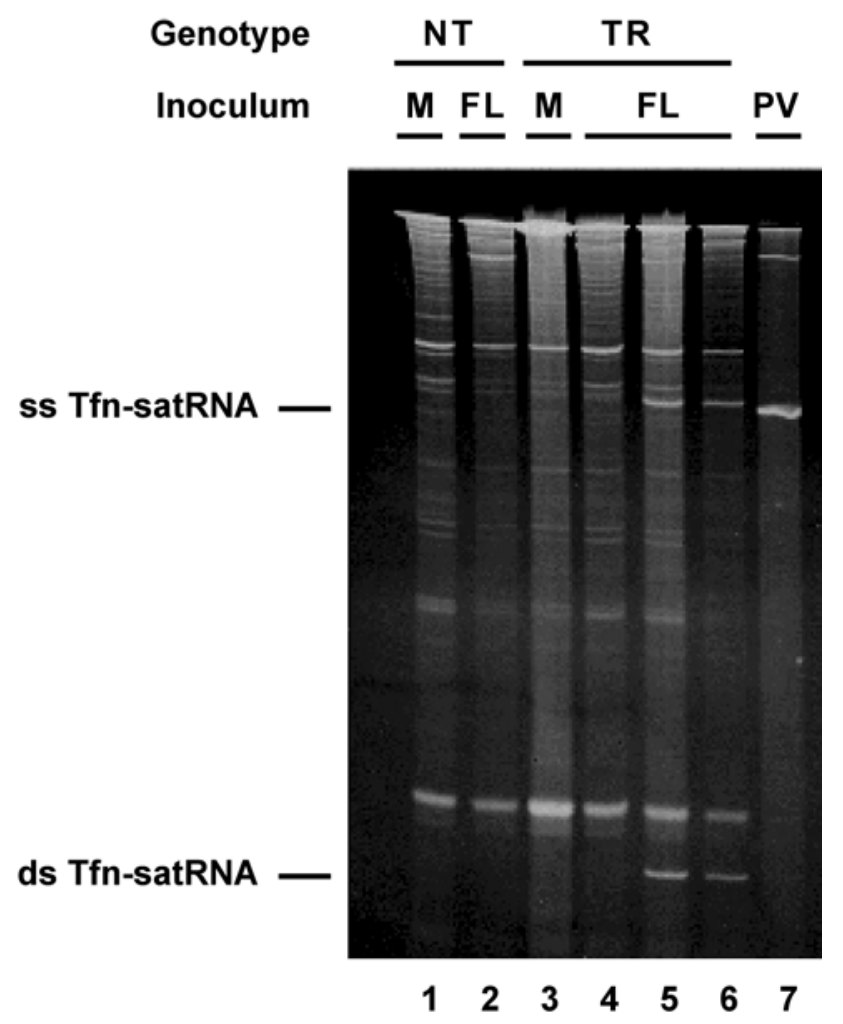

Fig. 1. Replication of endogenous Tfn-satellite (sat)RNA by the satRNA-free strain Cucumber mosaic virus (CMV)-FL. A, Northern blot hybridization analysis with a CMV RNA3-specific (top) and Tfn-satRNA-specific (bottom) riboprobe to $3 \mu \mathrm{g}$ of total nucleic acid extracted from UCTC5.9.2 transgenic (TR) and nontransgenic (NT) tomato plants inoculated with CMV-FL (FL) and CMV-Tfn (Tfn), or mock inoculated with buffer only (M). Exposure time for autoradiography was $2 \mathrm{~h}$. Both CMV genomic RNA3 and subgenomic RNA4 were detected by the RNA3-specific probe in lanes 3 and 4 after longer exposure (data not shown). B, Semidenaturing polyacrylamide gel electrophoresis stained with ethidium bromide, showing single-stranded (ss) and double-stranded (ds) CMV-Tfn-satRNA in $15 \mu \mathrm{g}$ of total nucleic acid extracted from TR and NT tomato plants inoculated with CMV-FL (FL) or mock inoculated (M). Samples were loaded on $9 \%$ polyacrylamide gel in semidenaturing conditions, in order to partially preserve the conformation of dssatRNAs and to denature ss-satRNAs. This results in a different electrophoretic mobility of ss-satRNAs (top of gel) and ds-satRNAs (bottom of gel). Lanes 4, 5, and 6 represent samples extracted at 3,6, and 9 days postinoculation, respectively. In lane 7, $3 \mu \mathrm{g}$ of RNA extracted from purified virus particles (PV) isolated from UCTC5.9.2 tomato plants inoculated with CMV-FL were loaded. 
satRNA-specific riboprobes revealed that all the mechanically inoculated plants were infected but there was a significant variation in the intensity of bands of RNAs 3 and 4 in transformed and untransformed plants. At $12 \mathrm{dpi}$, UC82 plants showed high accumulation of CMV-FL RNAs 3 and 4 and no satRNA-related bands (Fig. 1A, lane 2), while the transgenic genotype showed accumulation of a satRNA-related band with electrophoretic mobility corresponding to approximately 0.39 $\mathrm{kb}$ (Fig. 1A, lane 3) and very low hybridization signals corresponding to CMV RNAs 3 and 4. These signals were detectable only after longer exposure (data not shown). The CMV-FL inoculum did not contain any satRNA; therefore, the presence of this band was consistent with a CMV-driven replication of a mature Tfn-satRNA from the primary mRNA transcript (mTfnsatRNA) produced in transformed plants. A reduced accumulation of RNAs 3 and 4 and the replication of a $0.39-\mathrm{kb}$ satRNA also was evident in total nucleic acid extracts obtained from UC82 plants inoculated with a purified preparation of CMVTfn, containing its natural Tfn-satRNA (Fig. 1A, lane 4).

The occurrence of both single-stranded (ss)- and doublestranded (ds)-Tfn-satRNA in transformed plants provided further evidence for the novel production and active replication of Tfn-satRNA supported by CMV-FL. The ss- and ds-TfnsatRNAs can be separated readily and identified by their differ- ent electrophoretic mobility in semidenaturing polyacrylamide gel electrophoresis (PAGE) and sensitivity to RNase. In ethidium bromide-stained semidenaturing gels loaded with total nucleic acid extracts obtained from the above plants, ds-Tfn-satRNA was not detectable at 3 dpi (Fig. 1B, lane 4) but it clearly was visible at $6 \mathrm{dpi}$ in mechanically inoculated cotyledons (Fig. 1B, lane 5) and at 9 dpi in systemically infected leaves of transformed plants (Fig. 1B, lane 6). Tfn-satRNA was encapsidated in CMV-FL particles as judged from RNA preparations extracted from virions purified from transgenic plants 12 days after the challenge inoculation with CMV-FL (Fig. 1B, lane 7). Sequence analysis of cDNA obtained from reverse transcriptionpolymerase chain reaction (RT-PCR) of the encapsidated TfnsatRNA with the specific primer pair confirmed the 390-nt sequence of the transgene-derived mature form of Tfn-satRNA (data not shown).

The results of triple-antibody sandwich enzyme-linked immunosorbent assay (TAS-ELISA) obtained at weekly intervals (Table 1) showed that, after reaching a peak at $7 \mathrm{dpi}$, the CMVFL titer in untransformed plants decreased over the following 2 weeks, then remained constant over the remaining time course. On the other hand, the CMV-FL concentration in transgenic plants showed a dramatic decrease during the second week of infection, and the levels of viral accumulation remained very

Table 1. Differential accumulation, determined by enzyme-linked immunosorbent assay (ELISA) test, of Cucumber mosaic virus (CMV) particles in transgenic and control plants inoculated with CMV-FL

\begin{tabular}{|c|c|c|c|c|c|}
\hline \multirow[b]{2}{*}{ Plant line } & \multirow[b]{2}{*}{ Inoculum } & \multicolumn{4}{|c|}{ Days postinoculation $^{a}$} \\
\hline & & 7 & 14 & 21 & 28 \\
\hline UC82 & Mock & $0.008 \pm 0.004$ & $0.008 \pm 0.004$ & $0.008 \pm 0.002$ & $0.005 \pm 0.001$ \\
\hline UCTC5.9.2 & CMV-FL & $0.281 \pm 0.023$ & $0.068 \pm 0.009$ & $0.028 \pm 0.005$ & $0.049 \pm 0.022$ \\
\hline UC82 & CMV-FL & $0.545 \pm 0.058$ & $0.302 \pm 0.047$ & $0.153 \pm 0.054$ & $0.170 \pm 0.052$ \\
\hline
\end{tabular}

${ }^{a}$ Relative virus concentration was measured by triple-antibody sandwich ELISA. Five plants per test were inoculated, and average values of readings (optical density at $405 \mathrm{~nm}$ ) \pm standard deviations are shown.

Table 2. Development of lethal necrosis symptoms in transgenic and control tomato plants challenged with the Cucumber mosaic virus (CMV) necrogenic strain CMV-77

\begin{tabular}{|c|c|c|c|c|c|c|}
\hline \multirow[b]{2}{*}{ Plant line $e^{b}$} & \multirow[b]{2}{*}{ Inoculum } & \multirow[b]{2}{*}{ Conc. $(\mu \mathrm{g} / \mathrm{ml})^{\mathrm{c}}$} & \multicolumn{4}{|c|}{ Symptoms development $^{\mathrm{a}}$} \\
\hline & & & Recovery $^{d}$ & Stunting & Necrosis & Death \\
\hline \multicolumn{7}{|l|}{$7 \mathrm{dpi}$} \\
\hline \multirow[t]{3}{*}{ UCTC5.9.2 } & CMV-77 & 500 & $10 / 10$ & $\ldots$ & $\ldots$ & $\ldots$ \\
\hline & CMV-77 & 100 & $10 / 10$ & $\ldots$ & $\ldots$ & $\ldots$ \\
\hline & Mock $\mathrm{e}^{\mathrm{e}}$ & & $10 / 10$ & $\ldots$ & $\ldots$ & $\ldots$ \\
\hline \multirow[t]{3}{*}{ UC82 } & CMV-77 & 500 & $10 / 10$ & $\ldots$ & $\ldots$ & $\ldots$ \\
\hline & CMV-77 & 100 & $10 / 10$ & $\ldots$ & $\ldots$ & $\ldots$ \\
\hline & $\operatorname{Mock}^{\mathrm{e}}$ & $\ldots$ & $10 / 10$ & $\ldots$ & $\ldots$ & $\ldots$ \\
\hline \multicolumn{7}{|l|}{$15 \mathrm{dpi}$} \\
\hline \multirow[t]{2}{*}{ UCTC5.9.2 } & CMV-77 & 500 & $\ldots$ & $3 / 10$ & $7 / 10$ & $\ldots$ \\
\hline & CMV-77 & 100 & $\ldots$ & $6 / 10$ & $4 / 10$ & $\ldots$ \\
\hline \multirow[t]{2}{*}{ UC82 } & CMV-77 & 500 & $\ldots$ & $2 / 10$ & $8 / 10$ & $\ldots$ \\
\hline & CMV-77 & 100 & $\ldots$ & $2 / 10$ & $8 / 10$ & $\ldots$ \\
\hline \multicolumn{7}{|l|}{$21 \mathrm{dpi}$} \\
\hline \multirow[t]{2}{*}{ UCTC5.9.2 } & CMV-77 & 500 & $2 / 10$ & $\ldots$ & $\ldots$ & $8 / 10$ \\
\hline & CMV-77 & 100 & $8 / 10$ & $\ldots$ & $\ldots$ & $2 / 10$ \\
\hline \multirow[t]{2}{*}{ UC82 } & CMV-77 & 500 & $\ldots$ & $\ldots$ & $\ldots$ & $10 / 10$ \\
\hline & CMV-77 & 100 & $\ldots$ & $\ldots$ & $\ldots$ & $10 / 10$ \\
\hline \multicolumn{7}{|l|}{$30-60 \mathrm{dpi}$} \\
\hline \multirow[t]{2}{*}{ UCTC5.9.2 } & CMV-77 & 500 & $2 / 10$ & $\ldots$ & $\ldots$ & $\ldots$ \\
\hline & CMV-77 & 100 & $8 / 10$ & $\ldots$ & $\ldots$ & $\ldots$ \\
\hline \multirow[t]{2}{*}{ UC82 } & CMV-77 & 500 & $\ldots$ & $\ldots$ & $\ldots$ & $\ldots$ \\
\hline & CMV-77 & 100 & $\ldots$ & $\ldots$ & $\ldots$ & $\ldots$ \\
\hline
\end{tabular}


low afterward. Similar results were obtained by challenging UC82 and UCTC5.9.2 tomato plants with CMV-77.2 (i.e., with the CMV-77 strain artificially deprived of its satRNA; see below and Materials and Methods).

Taken together, the results described above indicate that plants of the UCTC5.9.2 transformed line were tolerant to symptom expression and down-regulated the accumulation of the challenge virus.

\section{Challenge inoculation with CMV-77,}

\section{a CMV strain supporting a necrogenic satRNA.}

In all, 10 UC.TC5.9.2 plants and 10 control UC82 plants were either inoculated with a purified preparation of CMV-77 at two different concentrations, 500 and $100 \mu \mathrm{g} / \mathrm{ml}$, or mock inoculated with buffer. Disease symptoms were scored at 7,15 , 21, 30, and 60 dpi (Table 2). Mock-inoculated plants remained asymptomatic and developed normally. Between 7 and 15 dpi, eight of ten inoculated untransformed plants developed leaf and stem necrosis, and all of them died within $21 \mathrm{dpi}$, independently of the concentration of the inoculum. Transformed plants inoculated with viral preparation at $500 \mu \mathrm{g} / \mathrm{ml}$ showed symptom development similar to that of untransformed plants, with only two of ten exhibiting a recovery from 21 dpi. Of 10 UC.TC5.9.2 plants challenged with virus inoculum at 100 $\mu \mathrm{g} / \mathrm{ml}$, four exhibited symptoms of leaf necrosis at $15 \mathrm{dpi}$. Two infected plants died by $21 \mathrm{dpi}$, whereas the remaining plants underwent a progressive change in the disease phenotype, because young upper leaves that emerged developed free of symptoms and were identical in appearance to the mock-inoculated plants. Therefore, a tolerance to lethal necrosis was shown in transgenic tomato plants, although this was concentration-dependent upon viral mechanical inoculation.

The dynamics of accumulation of both ss- and dsRNA forms of the exogenous 77-satRNA (strain CMV-77 supporting a necrogenic satRNA) introduced with the challenging inoculum, and of the endogenous Tfn-satRNA transcribed from the transgenic insert, were analyzed at 3 and 7 dpi (in total nucleic acid samples from the two inoculated cotyledons), and at 10, 17, 24, 30, and 60 dpi (in samples from the first, second, third, fourth, and sixth true leaves, respectively), by semidenaturing PAGE.
In a plant inoculated with virus at $500 \mu \mathrm{g} / \mathrm{ml}$ and exhibiting late recovery from necrosis (Fig. 2, plant 1), 77-satRNA was the predominant satellite RNA variant both in the inoculated cotyledon tissue at $7 \mathrm{dpi}$ (Fig. 2, lane 2) and in the systemically infected leaves at $17 \mathrm{dpi}$ (Fig. 2, lane 3). By $30 \mathrm{dpi}$, the accumulation of ss- and ds-77-satRNA in newly emerged leaves decreased and, by $60 \mathrm{dpi}$, they were no longer detectable (Fig. 2, lanes 5 and 6). By contrast, the accumulation of ss- and ds-TfnsatRNA progressively increased, equaling and surpassing the 77-satRNAs at 24 to 30 dpi (Fig. 2, lane 4 and 5). At the time when Tfn-satRNA became predominant (Fig. 2, lanes 5 and 6), the plant exhibited a progressive recovery from the necrotic phenotype and, by $60 \mathrm{dpi}$, the new leaves were completely free of symptoms.

In the cotyledons of a transgenic tomato plant inoculated with virus at $100 \mu \mathrm{g} / \mathrm{ml}$ (Fig. 2, plant 2), which recovered earlier from disease symptoms, the ss- and dsRNA bands corresponding to 77-satRNA already were undetectable at $7 \mathrm{dpi}$ with the concomitant appearance of ds-Tfn-satRNA (Fig. 2, lane 8, bottom panel). At this time, the accumulation of ss forms of both the satRNA variants in the infected leaves was below the limit of the detection (Fig. 2, lanes 7 and 8, top panel). In the upper, systemically infected leaves harvested at $10 \mathrm{dpi}$, ss- and dsRNA bands of the two satRNA variants had the same intensity (Fig. 2, lane 9); however, over the following 2 weeks, the accumulation of 77-satRNA in new leaves diminished progressively and, by $24 \mathrm{dpi}$ and thereafter, only the accumulation of ss and ds forms of Tfn-satRNA was detectable (Fig. 2, lanes 10 to 13). Concomitant absence of 77-satRNA in young, infected tissues and full recovery from leaf necrosis symptoms also was observed in this instance.

These results were observed consistently in two transgenic plants inoculated with virus at $500 \mu \mathrm{g} / \mathrm{ml}$ and in four transgenic plants inoculated with virus at $100 \mu \mathrm{g} / \mathrm{ml}$ (data not shown).

\section{Analysis of the satRNA progeny}

in transformed tomato plants infected with CMV-77.

In the biological system under study, two different variants of CMV satRNA are present simultaneously upon inoculation of CMV-77. The alignment of the nucleotide sequences of Tfn-

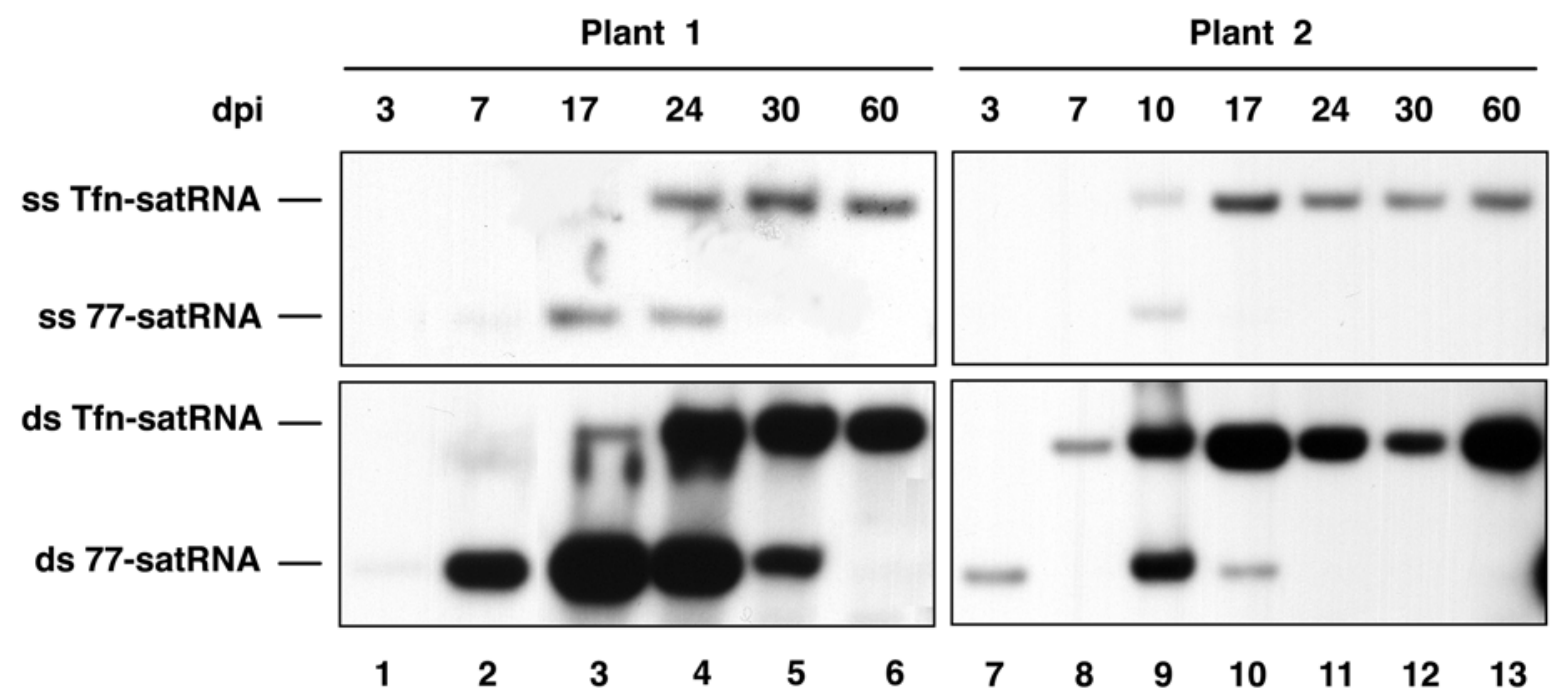

Fig. 2. Replication of endogenous Tfn-satellite (sat)RNA by Cucumber mosaic virus (CMV)-77, a strain supporting a necrogenic satRNA variant (77satRNA). Northern blot hybridization analysis with a mix of Tfn- and 77-satRNA-specific riboprobes to $15 \mu \mathrm{g}$ of total nucleic acid extracted from two different UCTC5.9.2 tomato plants (plant 1 and plant 2) at fixed times, as indicated at the top of the lanes. Total nucleic acid samples were extracted at 3 and 7 days postinoculation (dpi) from inoculated cotyledons (lanes 1, 2, 7, and 8), and by 10 dpi and thereafter from upper, systemically infected leaves. Samples were loaded on $9 \%$ polyacrylamide gel in semidenaturing conditions, in order to use the different electrophoretic mobility to differentiate singlestranded (ss)-satRNAs (shown in top panels) from double-stranded (ds)-satRNAs (shown in bottom panels). After alkaline denaturation of dsRNAs, samples were blotted onto nylon membrane. The exposure time for autoradiography was $72 \mathrm{~h}$. 
satRNA and 77-satRNA is shown in Figure 3A. The two vari-

1 GTTTTGTTTGTTGGAGACCCGCGCGGAGGGGATATATC. GंTGCGGTGATC 49 1 GTTTTGTTGATGGAGAATtGCGTAGAGGGGTATATCTGCGTGAGGATC 50 50 CTTCACTCGGCGGTGTGGGTTAACTCCCTGCTAAGGCGGGTTGGAGACTG 99

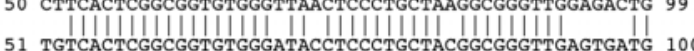
100 CGCCCGGGACAGGCCGGACCTTGGGGGAGCCCACGAGCCGCGTGGGAACG 149 $101 \underset{\text { TTCCCTCGGACTGGGGACCGCTGG. }}{|||| \ldots \ldots \ldots \ldots \ldots \ldots \ldots \ldots} 124$ 150 TAGCGGTTPCCGGTTGAACTGGTGCCGGAGGCCCTCAGCGGTTTGTTTCG 199 $125 \ldots \ldots \ldots \ldots \ldots \ldots \ldots \ldots \ldots \ldots$. 200 ACGCTTCCCTCCATTTGAGCCCCCGCTCAGTTTGCTAGCAAAACCCGGCA 249 152 TACTACACTCTCATtTGAGCCCCGCTCAGTtTGCTAGCAGAACCCGCA 201 250 CATGGTTCGCCGTTACCATGGATTTTCGAÄAGAAACACTCTGTTAGGTGG 299 II111111 111111 11111111111111111! 300 TATCAGTAGACGACGCACGCAGGGAGAGGCTAAAACCTTAATTGGTCATG 349

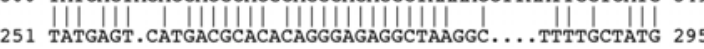
350 CTGATCTCCACACGTATGTCTATCATACCTTAACAGGACĆ 390 296 CTGATCTC. . CGTGAaTGTCTATCATTCCGAAACAGGACCd 334

B

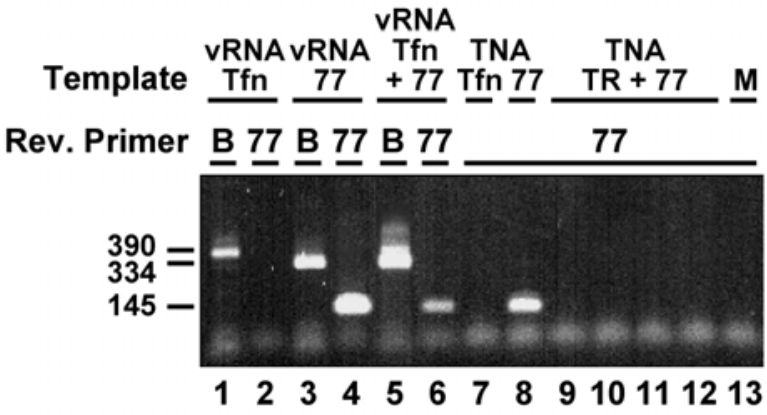

C

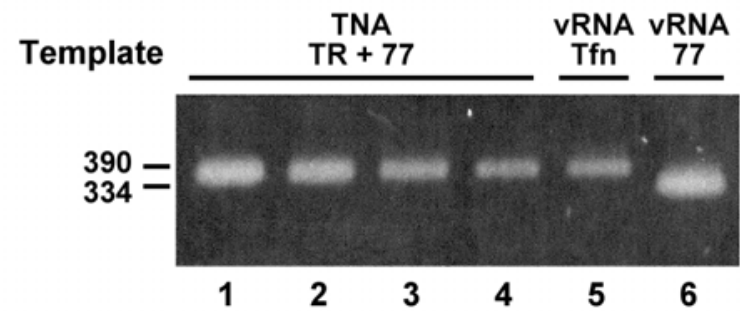

Fig. 3. Analysis of the satellite (sat)RNA progeny in transformed tomato plants infected with Cucumber mosaic virus (CMV)-77. A, Alignment of nucleotide sequences of Tfn-satRNA (top) and 77-satRNA (bottom). The underlined sequence (77-satRNA, nucleotides 109 to 139) has been chosen for the specific priming of 77-satRNA in reverse transcription-polymerase chain reaction (RT-PCR), using the reverse primer mid-77. The sequences recognized by the universal satRNA forward primer A and the universal satRNA reverse primer B are shown as empty and shadowed boxes, respectively. B, Agarose gel analysis of RT-PCR products stained with ethidium bromide obtained from RNA samples containing Tfn- or 77-satRNA. For control RT-PCR reactions, viral RNA (vRNA) from CMV-Tfn (lanes 1 and 2), CMV-77 (lanes 3 and 4), and a mixture of both CMV strains (lanes 5 and 6) were used as template. Total nucleic acid (TNA) samples for RT-PCR reactions were extracted 60 days postinoculation (dpi) from untransformed tomato plants inoculated with CMV-Tfn (lane 7) or CMV-77 (lane 8), and from UCTC5.9.2 tomato plants inoculated with CMV-77 (lanes 9-12) or mock inoculated (lane 13). The two different reverse primers, primer B, which anneals to all the known CMV satRNA sequences, or primer mid-77 (77), specific for 77-satRNA detection, were used along with the forward primer A as indicated at top of the picture. C, Agarose gel analysis of RTPCR products, obtained using universal primers $\mathrm{A}$ and $\mathrm{B}$, stained with ethidium bromide, from total nucleic acid extracted from UCTC5.9.2 tomato plants 60 dpi with CMV-77 (TR + 77, lanes 1-4), or from RNA extracted from purified particles of CMV-Tfn (lane 5) and CMV-77 (lane 6). Numbers at left side refer to the size (bp) of RT-PCR amplification products. ants showed an overall sequence similarity of $70 \%$, with two regions of 81 and $85 \%$ similarity in the $5^{\prime}$ - and $3^{\prime}$-proximal half, respectively. In the central region, there is very little sequence similarity, and this region was used for the differential detection of the two molecules.

To rule out the possibility that 77-satRNA simply escaped detection, total nucleic acid extracts obtained from UCTC5.9.2 leaf tissues, 60 dpi with CMV-77, were subjected to RT-PCR analysis either with satRNA universal primers A and B (boxed sequences in Fig. 3A) or with primer A and primer mid-77 (underlined in Fig. 3A). Universal primers A and B can amplify both satRNA variants in either separate (Fig. 3B, lanes 1 and 3) or the same RT-PCR mixture (Fig. 3B, lane 5). Mid-77 primer is complementary to a region in which there is poor sequence similarity between Tfn-satRNA and 77-satRNA and the amplified products confirm that (Fig. 3B, lanes 2, 4, 6, 7, and 8), with this primer, a 145-bp fragment can be amplified from 77satRNA but not from Tfn-satRNA when these molecules are contained either in separate (Fig. 3B, lanes 2, 4, 7, and 8) or in the same (Fig. 3B, lane 6) RT-PCR reactions. Therefore, primer mid-77 was used to prime total nucleic acid preparations extracted $60 \mathrm{dpi}$ from four different UCTC5.9.2 plants fully recovered from the symptoms of necrosis induced by CMV-77. The 77-satRNA-specific product of 145 bp was not amplified in any of them (Fig. 3B, lanes 9 to 12), whereas a Tfn-satRNA-specific product of approximately $390 \mathrm{bp}$ was amplified from the same total nucleic acid extracts primed with universal satRNA primers A and B (Fig. 3C, lanes 1 to 4 ). Similar results were obtained using the forward primer A instead of the reverse primer mid-77 in the RT step, in order to amplify the negative strand of the 77-satRNA (data not shown).

In order to further confirm the absence of 77-satRNA in the recovered plants, tissues from 60-day-old systemically infected leaves were extracted and used for mechanical inoculation of 'Xanthi' tobacco plants dusted with Celite. After three serial passages in tobacco, either total nucleic acid extracts or RNA preparations obtained from virus particles purified at each passage showed the presence of Tfn-satRNA but not of 77satRNA, when subjected to Northern blot hybridization or RTPCR (data not shown). These results confirmed that Tfn- but not 77-satRNA was present in the newly developed symptomfree leaf tissues.

The replication of two different variants of CMV-satRNA supported by a unique CMV strain in the same plant required assessing whether recombination might have occurred between the two molecules generating new satRNA species with potential damaging effects. Sequence analysis of RT-PCR amplicons obtained from total nucleic acid extracts of six UCTC5.9.2 plants with a 60-day-old infection showed that the population of Tfn-satRNA supported by CMV-77 in these plants had retained its original nucleotide sequence (data not shown).

\section{The tolerance phenotype may not be due} to the competition between Tfn-satRNA and 77-satRNA.

The results shown above suggest that the Tfn-satRNA-mediated tolerance to CMV-77-induced lethal necrosis symptoms may operate by two different mechanisms of interference with symptom expression, by i) competing for replication with both CMV-77 and its necrogenic satRNA or ii) reducing the accumulation level of CMV-77 by a sequence-specific, RNA-mediated degradation mechanism.

To study the first alternative, untransformed UC82 tomato plants were inoculated with RNA extracted from a purified preparation of CMV-77.2 alone, or together with transcripts, obtained in vitro from Tfn-satRNA and 77-satRNA cDNA 
clones, at different combinations of concentrations (Table 3). At 15 dpi, all plants inoculated with CMV-77.2 showed stunting and symptoms of leaf shoestring, whereas plants inoculated with CMV-77.2 + Tfn-satRNA appeared symptomless. The inoculum containing CMV-77.2 + 77-satRNA induced leaf and stem necrosis within $15 \mathrm{dpi}$. In the infections with mixtures of the two satRNA variants, early leaf and stem necrosis predominated except when the 77-satRNA concentration in the inoculum was reduced to 100 times less than that of Tfn-satRNA (Table 3). RNA gel blot analysis showed that plants inoculated with different mixtures of satRNA variants exhibited the selective accumulation of Tfn-satRNA only when the concentration of 77-satRNA in the inoculum was 1,000 times less than that of Tfn-satRNA (Table 3). At a 100-fold dilution of 77-satRNA in the inoculum, the two variants accumulated in approximately equal amounts, and plants showed delayed necrosis without dying but did not recover within 60 dpi. Thus, because accumulation of 77-satRNA in transgenic tomato plants inoculated with CMV-77 occurred earlier and to a higher extent than that of Tfn-satRNA (Fig. 2), the competition hypothesis seems untenable in explaining the observed suppression of 77-satRNA in transgenic tomato lines.

\section{RNA silencing-related events}

in transgenic tomato lines expressing Tfn-satRNA.

The second mechanism that could account for the 77satRNA suppression may involve a homology-dependent satRNA-induced silencing of the transgene. First, we tested whether a degradation of the Tfn-satRNA primary transcript (mTfn-satRNA) was detectable at the stage of infection when the accumulation level of 77-satRNA in new leaves declined. For this analysis, we used a riboprobe complementary to the NOS terminator sequence instead of a satRNA-specific probe, to avoid the interference derived from the hybridization signal of the mature form of replicating Tfn-satRNA. A time course of the expression level of mTfn-satRNA over a three-week period in total RNA extracted from UCTC5.9.2 plants after inoculation with CMV-77 is shown in Figure 4A. The expression of mTfn-satRNA can be detected at 7 dpi in the inoculated cotyledon leaves (Fig. 4A, lanes 3 to 5) and at 14 dpi in the systemically infected first true leaves (Fig. 4A, lanes 8 to 10), as well as in mock-inoculated plants of the same age (Fig. 4A, lanes 6 and 7). At $21 \mathrm{dpi}$, the level of mTfn-satRNA was greatly reduced in infected plants (Fig. 4A, lanes 13 to 15), although there was an apparent increase of mTfn-satRNA transcript in mock-inoculated plants (Fig. 4A, lanes 11 and 12).

In order to verify whether the presence of the Tfn-satRNA variant originated from the transgenic transcript and replicated by a satRNA-free CMV helper was sufficient to affect mTfnsatRNA accumulation in infected tissues, the expression level of the mTfn-satRNA at 21 dpi also was investigated in transgenic plants challenged with CMV-FL. The accumulation of mTfn-satRNA at $21 \mathrm{dpi}$ in mock-inoculated plants is shown in Figure 4B, lane 2. After infection with CMV-FL, the level of mTfn-satRNA exhibited only a weak signal at 21 dpi (Fig. 4B, lane 4). No hybridization was detected in RNA preparations obtained from nontransgenic tomato plants, either mock- (Fig. 4B, lane 1) or CMV-inoculated (Fig. 4B, lane 3). On the whole, these results suggest that i) mTfn-satRNA can be targeted by a mechanism of suppression elicited by the presence of the CMV-driven active replication of the satRNA originating from the transgene, ii) the activation of this mechanism seems independent from the presence of a second satRNA supplied in the inoculum, and iii) this mechanism shows similarities to PTGS.

To provide further evidence for the putative PTGS operating in transgenic tomato lines, experiments were carried out to investigate the presence of small interfering RNAs (siRNAs) that currently are indicated as the markers of RNA silencing phenomena (Elbashir et al. 2001; Hamilton and Baulcombe 1999). The gel blot analysis of low molecular weight RNA extracted from the same samples analyzed in Figure 4B is shown in Figure 4C. Mock-inoculated UC82 and UCTC5.9.2 tomato plants did not exhibit any hybridization signal corresponding to siRNAs in the range of 21 to $26 \mathrm{nt}$ (Fig. 4C, lanes 1 and 2). Upon hybridization with either the minus- (Fig. 4C) or plus-sense (data not shown) probes to Tfn-satRNA, a signal corresponding to siRNAs approximately $23 \mathrm{nt}$ in size, was detected in transgenic plants inoculated with CMV-FL (Fig. 4C, lane 4). A weak signal corresponding to siRNAs of approximately 23 nt also was detected in nontransgenic tomato plants inoculated with CMV-FL supplemented with Tfn-satRNA (Fig. 4C, lane 3). This latter result was not unexpected, because RNA silencing has been described as a natural mechanism of defense against viral infections in plants and other organisms (Voinnet 2001). However, the results of a densitometric analysis of the siRNA-related signal generated in four transgenic and four nontransgenic tomato plants upon viral infection show that, at 21 dpi., siRNAs corresponding to the Tfn-satRNA sequence produced in transgenic plants accumulated to a significantly higher level than that observed in nontransgenic plants (Table 4). In a sister experiment, the plants were challenged with CMV-77 carrying its natural 77-satRNA, and also, in this instance, a signal corresponding to satRNA-specific siRNAs was detected, in transgenic (Fig. 4D, lane 4) and, to a lesser extent, in nontransgenic (Fig. 4D, lane 2) tomato plants upon

Table 3. Symptom expression and satellite (sat)RNAs replication in untransformed tomato plants infected with Cucumber mosaic virus (CMV)-77.2 and different combinations of Tfn- and 77-satRNA

\begin{tabular}{|c|c|c|c|c|c|}
\hline \multicolumn{3}{|c|}{ Inoculum concentration $(\mu \mathrm{g} / \mathrm{ml})$} & \multirow[b]{2}{*}{ Symptoms ${ }^{\mathrm{b}}$} & \multicolumn{2}{|c|}{ RNA gel blot analysis ${ }^{a}$} \\
\hline CMV-77.2 & 77-satRNA & Tfn-satRNA & & 77-satRNA & Tfn-satRNA \\
\hline 50 & & & Shoestring leaf & - & - \\
\hline$\ldots$ & 5 & 5 & Necrosis & + & - \\
\hline$\ldots$ & 5 & $5 \times 10^{-1}$ & Necrosis & + & - \\
\hline $\begin{array}{l}\cdots \\
\cdots\end{array}$ & 5 & $5 \times 10^{-2}$ & Necrosis & + & - \\
\hline $\begin{array}{l}\cdots \\
\cdots\end{array}$ & 5 & $5 \times 10^{-3}$ & Necrosis & + & - \\
\hline$\ldots$ & 5 & $\ldots$ & Necrosis & + & - \\
\hline$\ldots$ & $5 \times 10^{-1}$ & 5 & Necrosis & + & _- \\
\hline$\ldots$ & $5 \times 10^{-2}$ & 5 & Delayed necrosis & + & + \\
\hline$\ldots$ & $5 \times 10^{-3}$ & 5 & Asymptomatic & - & + \\
\hline$\ldots$ & $\ldots$ & 5 & Asymptomatic & - & + \\
\hline
\end{tabular}

a Total nucleic acid extracts from plants inoculated with the indicated combinations of virus and satRNAs were electrophoresed on $1.2 \%$ agarose gel, blotted onto Hybond-N (Amersham Pharmacia) membranes, and hybridized with satRNA-specific probes. Detection of satRNA-specific hybridization signal is indicated by + and absence of signal is indicated by - .

${ }^{\mathrm{b}}$ Three plants per each combination of inoculum were individually screened for symptom phenotype and RNA gel blot analysis. 
A

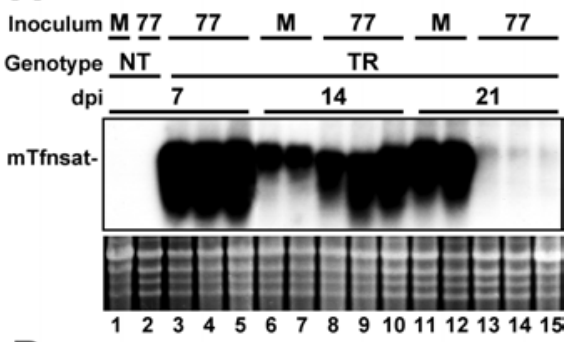

B

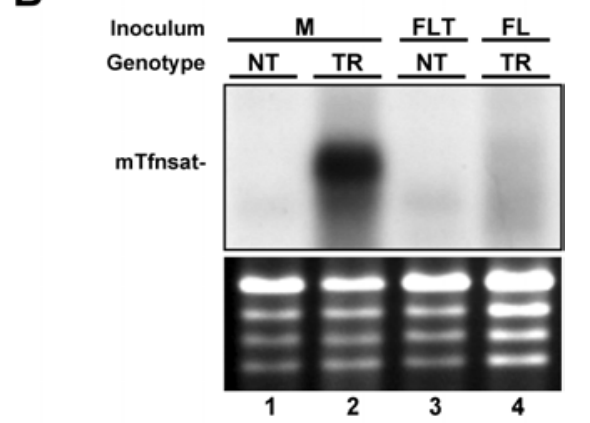

C

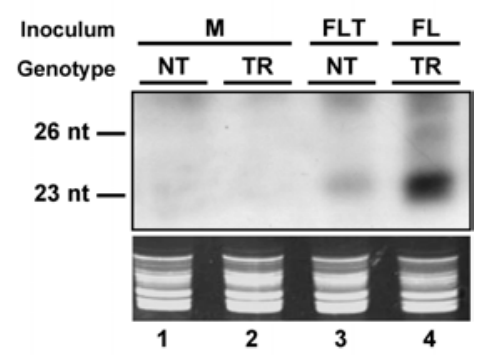

D

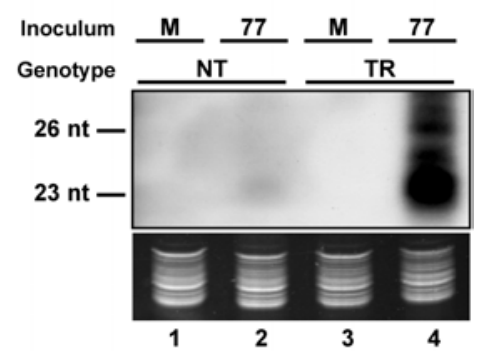

Fig. 4. A, Northern blot hybridization analysis with a NOS terminatorspecific probe to $20 \mu \mathrm{g}$ of total RNA extracted at 7, 14, and 21 days postinoculation (dpi) from UCTC5.9.2 tomato transgenic (TR) or control nontransgenic (NT) plants infected with Cucumber mosaic virus (CMV)77 (77) or mock inoculated (M). Different accumulation levels of the primary transcripts of the transgenic messenger Tfn-satellite RNA (mTfnsat) are shown. The exposure time for autoradiography was $96 \mathrm{~h}$. B, Northern blot hybridization analysis with a NOS terminator-specific probe to $20 \mu \mathrm{g}$ of total RNA extracted at 21 dpi from UCTC5.9.2 TR or control NT plants infected with CMV-FL (FL), CMV-FL supplemented with an in vitro transcript of Tfn-satRNA (FLT), or mock inoculated (M). Different accumulation levels of the primary transcripts of the transgenic mTfnsatRNA are shown. The exposure time for autoradiography was $96 \mathrm{~h}$. C, Detection of small interfering (si)RNAs to the Tfn-satRNA sequence with a specific (-)-sense Tfn-satRNA probe. Samples are the same as in B. Total RNAs were enriched for low molecular weight RNAs, loaded on a $15 \%$ polyacrylamide gel electrophoresis, and blotted on a positively charged nylon membrane. Two DNA oligonucleotides, 23 and 26 nucleotides (nt) long, were run together with RNA samples, and their electrophoretic mobility as observed by ethidium bromide staining of the gel is indicated on the left side of the top panel. The exposure time for autoradiography was 9 days. D, Detection of siRNAs with a specific (-)-sense 77-satRNA probe in total RNA extracted at 21 dpi from UCTC5.9.2 TR or control NT plants infected with CMV-77 (77) or mock inoculated (M). The exposure time for autoradiography was 11 days. Ethidium bromide staining of rRNAs, run on the different gels employed for RNA blotting, was used to confirm equal loading of samples in all lanes. hybridization with either the minus- or plus-sense (data not shown) probes to 77-satRNA. Therefore, the suppression of satRNA sequences in transgenic tomato plants undergoing recovery from CMV-77-induced disease symptoms correlates positively with reduced transcription of mTfn-satRNA and substantial overproduction of satRNA-specific siRNAs of approximately 23 nt.

Overall, these results support the hypothesis for the presence of an RNA silencing mechanism, which seems to be inactive in the first stages of virus infection, because it is induced by the active CMV-driven satRNA replication, and targets the endogenous mTfn-satRNA as well as exogenous sequences sharing nucleotide sequence similarity with the transgene.

\section{DISCUSSION}

We have introduced a DNA construct into 'UC82' tomato plants whose transcript bears a single full-length copy of CMV-Tfn-sat-RNA. Following infection with a satRNA-free strain of CMV, unit-length satRNA was rescued from the endogenous precursor transcript, replicated, and packaged in viral particles with elimination of non-satRNA flanking sequences. The transgenically expressed Tfn-satRNA was able to downregulate replication of both CMV-FL, a CMV strain of subgroup IB, and CMV-77.2, a CMV strain of subgroup IA that was made satRNA-free in our laboratory. As a result, plants of the transgenic tomato line UCTC5.9.2 expressing Tfn-satRNA were tolerant to symptom production and down-regulated the replication of the challenging virus. These data are in agreement with the several examples that have been reported, in which CMV tolerance in tomato results from transgenic expression of symptom-ameliorating satellites (Jacquemond and Tepfer 1998; Garcia-Arenal and Palukaitis 1999).

Besides the evidence of the resistance to satRNA-free strains of $\mathrm{CMV}$, this work provides new insights on what happens when transgenic plants expressing a benign CMV-satRNA are infected with a CMV inoculum containing a necrogenic satRNA. No data were available thus far for transgenic plants, although the inverse combination (a necrogenic satRNA-expressing transgenic tomato line challenged with a CMV strain supporting a benign satRNA) has been tested by Jacquemond and Tepfer (1998), and some data have been provided by infecting untransformed plants with inocula containing variable amounts of the two satRNA variants supported by the same CMV strain (Jacquemond and Lot 1981; Smith et al. 1992; this study). In all these instances, a dominance of replication and symptom determination of the necrogenic satRNA over the nonnecrogenic molecule was demonstrated clearly.

By analogy with these results, it might be envisaged that, in the transgenic tomato line UCTC5.9.2, Tfn-satRNA also could down-regulate the replication of its helper virus but not to outcompete the replication of a necrogenic satRNA. Considering our contrary observations, we propose that the tolerance to $\mathrm{CMV}-77$ in this transgenic tomato line is not due to simple competition for replication between different satRNAs, but is mediated by a molecular mechanism that degrades homologous satRNA sequences in infected tissues and rules out any competitive advantage of the exogenous necrogenic over the endogenous nonnecrogenic satRNA. In fact, this work provides evidence of a close correlation between the disappearance of necrogenic 77-satRNA, the subsequent recovery phenotype, and two phenomena that are hallmarks of RNA silencing (Voinnet 2001; Waterhouse et al. 2001), i.e., the strong reduction of the accumulation level of the transgenic messenger RNA and the accumulation of low molecular weight RNAs, approximately 21 to $25 \mathrm{nt}$ long, with sequence homology to the transgene. 
Gene silencing has been proposed as a general strategy used by host plants as a natural defense mechanism against viral infection. The anomalous presence of dsRNA in the cell, generated as by-product of viral replication, functions as the trigger of a process leading to degradation of the foreign and potentially pathogenic nucleic acid (Covey et al. 1997; Ratcliff et al. 1997; Vance and Vaucheret 2001). Our finding that siRNAs of approximately $23 \mathrm{nt}$, homologous to CMV satRNA sequences, accumulate in infected nontransformed tomato plants, thus is consistent with this general model of RNA-mediated defense response to viruses and shows, for the first time, the extent of such a response in the case of CMV-satRNA infections. For this mechanism, we propose the name of satRNA-induced gene silencing (SIGS). A similar process has been described in tomato plants infected by Potato spindle tuber viroid (Itaya et al. 2001, Papaefthimiou et al. 2001). By analogy with the models proposed in other systems, ds-satRNAs that are formed and accumulated at high levels during CMV-driven satRNA replication (Fig. 2) would be targeted for degradation by a Dicer-like nuclease (Bernstein et al. 2001), generating siRNAs that are approximately $23 \mathrm{nt}$ long. In naturally occurring infections, it is conceivable that equilibrium is created between satRNA degradation by SIGS and new production of satRNA operated by the CMV replicative complex. Nevertheless, this equilibrium does not affect the ability of satRNAs and their helper virus to determine the range of well-known disease symptoms.

When CMV supporting a necrogenic satRNA (e.g., CMV-77 strain in our study) infects transgenic tomato plants expressing the benign variant Tfn-satRNA, two events could shift the equilibrium in favor of the recovery and the maintenance of a symptomless phenotype: i) the amplification of the SIGS response and ii) the reinforced ability of Tfn-satRNA to outcompete 77-satRNA for replication in the presence of the SIGS process. The first event, leading to the suppression of the transgene expression rapidly extending throughout the plant, is known to be due to the presence of the transgene itself, and requires the active transcription of the transgenic sequences (Palauqui et al. 1997; Voinnet 2001). In our model, siRNAs accumulated in infected transgenic plants at a significantly higher level than observed in nontransgenic tomato by $21 \mathrm{dpi}$, thus indicating that, in the presence of the Tfn-satRNA transcribed from the transgene and replicated by the helper CMV strain, the SIGS mechanism progresses more efficiently and extensively than in nontransgenic plants challenged with the same combination of CMV-satRNA (Fig. 4; Table 4). The siRNAs deriving from ds-satRNA turnover and accumulating in this phase probably have an active role in directing the RNA degradation process in a sequence-specific manner in association with some plant nuclease relative to the RNA-induced silencing complex (RISC) described in Drosophila (Hammond et al. 2000), thus serving as guide for identification and degradation of homologous ssRNAs, like mTfn-satRNA transcripts and both satRNA variants (Tfn and 77) replicated in association with CMV infection. In fact, the two satRNA variants share in their 3 -half three regions of at least $21 \mathrm{nt}$ completely identical in sequence. This is the minimum sequence homology required to allow siRNAs generated to the transgene to bind and target for degradation similar RNA species (Elbashir et al. 2001).

The second event (i.e., the possibility for the benign TfnsatRNA to outcompete the necrogenic variant for replication and symptom expression) could be determined by the fact that, unlike other virus-induced gene silencing (VIGS) models, SIGS does not target CMV directly and, as a consequence, replication and systemic infection of the helper virus, although down-regulated, progress normally. A similar satellite virusinduced silencing mechanism has been exploited by Gosselé and associates (2002) to obtain increased levels of transient systemic gene silencing in plants inoculated with Tobacco mosaic virus and its satellite virus used as a vector of inhibitory sequences. To explain why Tfn-satRNA survives the suppression operated by the RNA silencing process, it should be considered that mTfn-satRNA could be rescued by the viral replicase to a mature form of satRNA in silenced cells, even starting from a low amount of primary transcript, as soon as both the virus and the silencing signal spread systemically through the plant. Thus, a balance could be reached between TfnsatRNA SIGS-dependent degradation and Tfn-satRNA replication and accumulation operated by the helper virus from a few surviving molecules. This would not be the case of 77-satRNA which, unlike Tfn-satRNA, is not expressed at the single cell level. Because of the SIGS suppression process, 77-satRNA accumulation is, in fact, progressively reduced in new leaves, and might be driven to levels approximately 1,000 times less than that of Tfn-satRNA. With this imbalance of concentration, data presented in Table 3 demonstrates that Tfn-satRNA would be amplified preferentially as the unique satRNA variant. However, we cannot rule out the possibility that the two satRNA variants, both being strong inducers of SIGS, are targeted differently by the RISC-like nuclease. Tfn-satRNA might be more resistant to degradation than 77-satRNA, which would explain why the former is maintained whereas the latter is progressively eliminated. Such a differential sensitivity to silencing of RNA species sharing nucleotide sequence homology has been reported for defective interfering RNAs of tombusviruses (Szittya et al. 2002).

A CMV-encoded protein, named CMV-2b, has been described as an active suppressor of PTGS (Brigneti et al. 1998; Li et al. 1999). At present, we do not know which role 2 b protein may play in the SIGS model described in this article, although it may be possible that the satRNA-mediated down-regulation of CMV infection also reduces the $2 \mathrm{~b}$ level and, as a consequence, affects the viral function of RNA silencing suppression.

In this work, we also show that SIGS-mediated tolerance to tomato lethal necrosis and the establishment of the recovery phenotype is concentration-dependent upon mechanical inoculation of CMV on transgenic plants. In other words, the SIGS-

Table 4. Quantification of the level of Tfn-satellite (sat)RNA-specific small interfering (si)RNAs in transformed and nontransformed tomato plants upon Cucumber mosaic virus (CMV) infection

\begin{tabular}{llcc}
\hline Plant line & Inoculum $(\boldsymbol{\mu g} / \mathbf{m l})$ & siRNA band intensity (adj. vol.) & \\
\hline UC.TC5.9.2 & CMV-FL (50) & $4.68 \pm 0.65$ & Yes \\
UC82 & CMV-FL (50) + Tfn-satRNA (5) & $1.67 \pm 0.57$ & Yes \\
UC.TC5.9.2 & Mock & 0.00 & Yes \\
\hline
\end{tabular}

${ }^{a}$ Volume is the intensity data inside a defined boundary drawn on a gel blot image and including siRNA band signals. It is calculated as the sum of the intensities of the pixels within the volume boundary $\times$ pixel area, and expressed in optical density $\times \mathrm{mm}^{2} \times 10^{13}$. Adjusted volume (Adj. Vol.) is the total volume minus the background volume, calculated on mock-inoculated transgenic samples where no bands were detectable. Band intensity data were obtained through a Chemi Doc Image Analysis System (Bio-Rad). Four plants per genotype were inoculated, and mean value and standard deviation of readings is shown.

${ }^{\mathrm{b}} \mathrm{SD}=$ significant difference. Statistical analysis of data was performed by Duncan's multiple range test, and all mean values resulted significantly different between each other $(P=0.01)$. 
based equilibrium between satRNA accumulation and degradation would not work in the presence of a massive amount of helper virus and necrogenic satRNA primary inoculum. An explanation for this could be represented by the ability of necrogenic satRNAs to induce a complex plant defense response early in their infection, also involving programmed cell death (Xu et al. 2003). Therefore, the effects of this response could be extensive and irreversible, despite the transgenic protection, when employing high viral concentration for inoculating young tomato seedlings. In this regard, it also should be noted that a complete satellite RNA-induced PTGS did not occur immediately in our model system, but took place by approximately 21 dpi, similarly to other reported VIGS examples (Itaya et al. 2001; Jones et al. 1999; Ruiz et al. 1998).

A last consideration regards potential ecological risks associated with the use of these transgenic tomato lines expressing Tfn-satRNA in the field. In our experimental model, the observation that a satRNA variant different from transgenically expressed Tfn-satRNA is completely suppressed in the transformed plants by the first 20 to 30 days of infection means that, by this time post infection, no satRNA forms other than the ameliorative satRNA are available to the viral replicase for amplification and to viral particles for encapsidation and subsequent aphid-mediated dissemination. This results, together with the sequencing data on genetic stability of TfnsatRNA progeny after serial passages on tomato and tobacco reported here, lead to the conclusion that the appearance of new, aggressive satRNA variants generated by mutations or recombination from Tfn-satRNA expressing tomato plants is a rather unlikely event.

\section{MATERIALS AND METHODS}

\section{Plant transformation.}

A cDNA fragment corresponding to the full-length sequence of CMV-Tfn satRNA (390 nt) was amplified by PCR from clone pTfnC5.19 (Crescenzi et al. 1993), using oligonucleotides 5'-AAATCTAGAGTTTTGTTTGTTGGAGA-3', with a $X b a \mathrm{I}$ site preceding $17 \mathrm{nt}$ corresponding to the sequence of the $5^{\prime}$ terminus of Tfn-satRNA, as the forward primer (Sat-F primer), and 5'-AAATCTAGAGCTCGGGTCCTGTTAAGGTAT-3', with $\mathrm{XbaI}$ and $\mathrm{SacI}$ sites preceding 17 nt complementary to those of the $3^{\prime}$ terminus of Tfn-satRNA, as the reverse primer (Sat-R primer).

The amplified fragment was inserted between the XbaI and SacI sites of the binary plant transformation vector pBI121 (Clontech, Palo Alto, CA, U.S.A.), replacing the corresponding $\beta$-glucuronidase (gus) gene sequence, and cloned in Escherichia coli DH5 $\alpha$. The deriving plasmid pBI.TC5.16 was extracted and used to transform Agrobacterium tumefaciens LBA4404 according to the protocol of Holsters and associates (1978).

Tomato cv. UC82 cotyledons, explanted from aseptically grown seedlings, were infected with $A$. tumefaciens containing the plant expression vector, and were regenerated into whole plants according to McCormick (1991). To yield $T_{1}$ seed, the $\mathrm{T}_{0}$ generation plants were transferred to soil and adapted gradually to glasshouse environmental conditions. Homozygous individuals were selected from $T_{1}$ and $T_{2}$ progenies on the basis of kanamycin resistance.

\section{DNA and RNA analysis of transgenic plants.}

The presence of the transgene was assessed by PCR amplification as reported by McGarvey and Kaper (1991). The genomic DNA was screened both for the presence of TfnsatRNA sequence, using the specific Sat-F and Sat-R primers, and for the presence of nptII, using the forward primer $5^{\prime}$ -
AAAGGATCCCCCCTCGGTATCCAATTAGAG-3' and the reverse primer 5'-AAATCTAGACGGGGGGTGGGCGAAGAACTCCAG-3'.

For Southern blot hybridization analysis, $15 \mu \mathrm{g}$ of genomic DNA extracted from each plant as described by Dellaporta and associates (1983) were digested with $X b a \mathrm{I}$, and were electrophoresed, blotted, and hybridized with a Tfn-satRNA-specific DNA probe labeled with $\alpha-{ }^{32} \mathrm{P}$ dCTP following standard protocols (Sambrook and Russell 2001).

Total RNA from transgenic plants was extracted according to Verwoerd and associates (1989). For Northern blotting, 15 $\mu \mathrm{g}$ of total RNA from each plant were denatured and electrophoresed in $1.2 \%$ agarose gel containing $6 \%$ (vol/vol) formaldehyde in morpholinepropanesulfonic acid (MOPS) buffer (Sambrook and Russel 2001). RNA was transferred to Hybond-N membrane (Amersham Pharmacia Biotech, Buckinghamshire, U.K.), bound by UV crosslinking, and hybridized at $62^{\circ} \mathrm{C}$ with a riboprobe labeled with $\alpha-{ }_{-}^{32} \mathrm{P}$ UTP specific for Tfn-satRNA, transcribed with SP6/T7 transcription kit (Roche Diagnostics, Mannheim, Germany) from pGEM.TfnC5.11 plasmid, linearized at the $\mathrm{Xba \textrm {I }}$ site (minus-strand probe).

\section{Virus source and challenge inoculations.}

The CMV strains denoted CMV-Tfn, CMV-FL (Crescenzi et al. 1993), and CMV-77 (Grieco et al. 1997) were used in this study. CMV-FL is a subgroup IB (Finetti-Sialer et al. 1999) satRNA-free strain, whereas CMV-Tfn (subgroup IB; FinettiSialer et al. 1999, Roossinck 2002) and CMV-77 (subgroup IA; Finetti-Sialer et al. 1999) both support a satRNA that are, respectively, benign and necrogenic in tomato. A satellite-free strain of CMV-77 (denoted CMV-77.2) was prepared according to Smith and associates (1992) by sucrose density gradient fractionation and serial inoculations of a single local lesion onto Chenopodium quinoa. The absence of satRNA was assessed by serial mechanical inoculations onto 'Xanthi' tobacco plants and RT-PCR analysis of total nucleic acid extracts (discussed below). All the isolates were maintained in 'Rutgers' tomato, and purified from systemically infected leaves collected 12 days after inoculation, according to Lot and associates (1972).

Transformed and untransformed tomato plants were mechanically inoculated at the cotyledon stage. Purified virus (5 $\mu \mathrm{l})$ at 50,100 , or $500 \mu \mathrm{g} / \mathrm{ml}$ in $30 \mathrm{mM} \mathrm{Na} \mathrm{HPO}_{4}$ was applied to each cotyledon dusted with Celite. Infectious satRNA transcripts were synthesized by in vitro transcription of linearized plasmids containing satRNA cDNAs with T7 RNA polymerase, according to described methods (Crescenzi et al., 1993), and inoculated at a concentration of $5 \mu \mathrm{g} / \mathrm{ml}$. Prior to inoculation onto tomato seedlings, virus infectivity was estimated by counting the number of local lesions induced in $C$. quinoa. Tomato plants mock inoculated with buffer served as negative control. After inoculation, plants were kept in the glasshouse at $24 \pm 2{ }^{\circ} \mathrm{C}$, with a 16 -h photoperiod, and were observed for disease symptoms every week for a minimum of 2 months.

The CMV titer in tomato leaves harvested randomly 1, 2, 3, and 4 weeks after the challenge inoculation was estimated by TAS-ELISA (Torrance 1992). ELISA plates were coated with a 1:5000 dilution of the polyclonal antibody CMV-CAR, and virus was detected by the monoclonal antibody CMV-172 diluted 1:1000 (both antibodies were courtesy of G. Grassi, Istituto Sperimentale per le Colture Industriali, MiPA, Bologna, Italy).

\section{Nucleic acid extraction and analysis.}

Total nucleic acids were extracted from $50 \mathrm{mg}$ leaf tissue of inoculated plants and controls, electrophoresed either through a $1.2 \%$ denaturing agarose gel or, for viral ss- and dsRNA analy- 
sis, through a $9 \%$ semidenaturing PAGE, and transferred to nylon membranes as described by White and Kaper (1989). Northern blots were hybridized with ${ }^{32} \mathrm{P}$-labeled riboprobes specific for Tfn-satRNA, 77-satRNA, or CMV RNA-3 synthesized by in vitro transcription with the SP6/T7 transcription kit (Roche Diagnostics), from linearized pGEM plasmids (Promega Corp., Madison, WI, U.S.A.) carrying the corresponding cDNAs.

For RT-PCR, $3 \mu \mathrm{g}$ of total nucleic acid treated with RNasefree DNase I or $1 \mu \mathrm{g}$ of viral RNA were mixed with 50 pmol of appropriate reverse primer in a total volume of $12.5 \mu$ containing $0.01 \%$ Triton $\mathrm{X}-100$, heated at $95^{\circ} \mathrm{C}$ for $3 \mathrm{~min}$, and quickly cooled on ice. Reverse transcription was performed for $1 \mathrm{~h}$ at $42^{\circ} \mathrm{C}$ in a total volume of $20 \mu \mathrm{l}$ containing the RNA-primer mixture: $1 \times$ RT buffer; $1 \mathrm{mM}$ dithiothreitol; $0.5 \mathrm{mM}$ dATP, dCTP, dGTP, and dTTP; ribonuclease inhibitor (Promega) at $1.5 \mathrm{U} / \mu \mathrm{l}$; and AMV reverse transcriptase (Gibco BRL Life Technologies, Gaithersburg, MD, U.S.A.) at $10 \mathrm{U} / \mu \mathrm{l}$. The amplification reactions were performed in a total volume of $100 \mu \mathrm{l}$ containing $10 \mu \mathrm{l}$ of the first strand reaction; $1 \times$ PCR buffer (Roche Diagnostics); $1.5 \mathrm{mM} \mathrm{MgCl}_{2} ; 0.5 \mu \mathrm{M}$ of each primers; $0.2 \mathrm{mM}$ dATP, dCTP, dGTP, and dTTP; and $5 \mathrm{U}$ of Taq DNA polymerase (Roche Diagnostics). The reactions were run in a DNA Thermal cycler (PE Applied Biosystem, Foster City, CA, U.S.A.) with a first denaturation cycle at $94^{\circ} \mathrm{C}$ for 5 min, followed by 35 cycles at alternating temperatures of $94^{\circ} \mathrm{C}$ $(1 \mathrm{~min}), 55^{\circ} \mathrm{C}(1 \mathrm{~min})$, and $72^{\circ} \mathrm{C}(2 \mathrm{~min})$.

Universal primers specific for satRNA sequences (Grieco et al. 1997), named A (forward primer, 5'-AAGGATCCGT TTTGTTTG(A,T)T(A,G)GAGAATTGCG(C,T)(A,G)GAG-3') and $B$ (reverse primer, 5'-AAGGATCCGGGTCCTG(C,G,T) (A,G,T)(A,G,T)(A,G,T)GGAATG-3'), degenerated for RT-PCR amplification of any variants of satRNA according to published nucleotide sequences, were used for simultaneous detection of Tfn and 77-satRNAs in infected plants. The primer $5^{\prime}$ GACATAGCTCGCAAGCCAGCGGTCCCCAGTC-3' (named mid-77), complementary to positions 109 to 139 of CMV-77 satRNA (accession number X86422), a region in which there is little sequence homology between 77-satRNA and-Tfn satRNA, was used as reverse primer for the selective detection of 77satRNA over Tfn-satRNA in infected transgenic plants. With this primer, the annealing temperature was set at $65^{\circ} \mathrm{C}$.

\section{Analysis of low molecular weight RNAs.}

Total RNA was extracted from plants (200 to $300 \mathrm{mg}$ of leaf tissues) by TRIZOL Reagent (Gibco BRL), purified, enriched for small RNAs by RNeasy Plant Mini Kit (Qiagen, Chatsworth, CA, U.S.A.), electrophoresed, and blotted onto Hybond-N membrane according to Di Serio and associates (2001). RNA $(5 \mu \mathrm{g})$ was loaded for PAGE analysis. Northern blot hybridizations were carried out, with either Tfn- or 77-satRNA-specific $\alpha-{ }^{32} \mathrm{P}-\mathrm{UTP}$-labeled riboprobes of either senses, at $35^{\circ} \mathrm{C}$ as described by Hamilton and Baulcombe (1999). The intensity of each individual siRNA band and relative quantification of RNA was determined using a Chemi Doc Image Analysis System (Bio-Rad, Hercules, CA, U.S.A.).

\section{Sequence analysis.}

Viral satellite RNA and total nucleic acid extracts prepared from six UCTC5.9.2 plants with a 60-day-old CMV-77 infection were treated with DNase I, primed with Sat-F and Sat-R, and subjected to RT-PCR as described above. Amplicons were eluted from agarose gels, cloned in pGEM-T vectors (Promega Corp.) according to standard procedures, and sequenced with T7 DNA polymerase (Sequenase, U.S. Biochemical, Cleveland, OH, U.S.A.). Eight independent clones were sequenced.

\section{ACKNOWLEDGMENTS}

This work was supported by a grant of MIPAF, D.M. 121/7240/96 del 14.6.96, prog. 171 in the framework of Piano Nazionale "Biotecnologie Vegetali" and MURST in the framework of CEGBA, University of Bari.

\section{LITERATURE CITED}

Baulcombe, D. C. 1996. Mechanism of pathogen-derived resistance to viruses in transgenic plants. Plant Cell 8:1833-1844.

Bernstein, E., Caudy, A. A., Hammond, S. M.., and Hannon, G. J. 2001 Role for a bidentate ribonuclease in the initiation step of RNA interference. Nature 409:363-366.

Brigneti, G., Voinnet, O., Li, W. X., Ji, L. H., Ding, S. W., and Baulcombe, D. C. 1998. Viral pathogenicity determinants are suppressors of transgene silencing in Nicotiana benthamiana. EMBO (Eur. Mol. Biol. Organ.) J. 17:6739-6746.

Collmer, C. W., and Howell, S. H. 1992. Role of satellite RNA in the expression of symptoms caused by plant viruses. Annu. Rev. Phytopathol. 30:419-442.

Covey, S. N., Al-Kaff, N. S., Langara, A., and Turner, D. S. 1997. Plants combat infection by gene silencing. Nature 385:781-782.

Crescenzi, A., Barbarossa, L., Cillo, F., Di Franco, A., Vovlas, N., and Gallitelli, D. 1993. Role of cucumber mosaic virus and its satellite RNA in the etiology of tomato fruit necrosis in Italy. Arch. Virol. 131:321-333.

Dellaporta, S. L., Wood, J., and Hicks, J. B. 1983. A plant DNA minipreparation: Version II. Plant Mol. Biol. Rep. 1:19-21.

Di Serio, F., Schob, H., Iglesias, A., Tarina, C., Bouldoires, E., and Meins, F., Jr. 2001. Sense- and antisense-mediated gene silencing in tobacco is inhibited by the same viral suppressors and is associated with accumulation of small RNAs. Proc. Natl. Acad. Sci. USA 98:6506-6510.

Elbashir, S. M., Lendeckel, W., and Tuschl, T. 2001. RNA interference is mediated by 21 - and 22-nucleotide RNAs. Genes Dev. 15:188-200.

Finetti-Sialer, M. M., Cillo, F., Barbarossa, L., and Gallitelli, D. 1999. Differentiation of cucumber mosaic virus subgroups by RT-PCR RFLP. J. Plant Pathol. 81:145-148.

Gallitelli, D. 1998. Present status of controlling cucumber mosaic virus. Pages 507-523 in: Plant Virus Disease Control. A. Hadidi, R. H. Khetarpal, and H. Koganezawa, eds. American Phytopathological Society Press, St. Paul, MN.

Gallitelli, D., Grieco, F., and Cillo, F. 1997. The potential of a beneficial satellite RNA of cucumber mosaic cucumovirus to acquire deleterious functions: nature versus greenhouses. Pages 100-106 in: Virus-Resistant Transgenic Plants: Potential Ecological Impact. M. Tepfer and E. Balàsz, eds. Springer-Verlag, Berlin and INRA, Paris.

Garcia-Arenal, F., and Palukaitis, P. 1999. Structure and functional relationships of satellite RNAs of cucumber mosaic virus. Pages 37-63 in: Current Topics in Microbiology and Immunology. Vol. 239. Satellites and Defective Viral RNAs. Springer-Verlag, Berlin.

Gosselé, V., Faché, I., Meulewaeter, F., Cornelissen, M., and Metzlaff, M. 2002. SVISS - a novel transient gene silencing system for gene function discovery and validation in tobacco plants Plant J. 32:859-866.

Grieco, F., La Nave, C., and Gallitelli, D. 1997. Evolutionary dynamics of cucumber mosaic virus satellite RNA during natural epidemics in Italy. Virology 229:166-174.

Hamilton, A. J., and Baulcombe, D. C. 1999. A species of small antisense RNA in posttranscriptional gene silencing in plants. Science 286:950952.

Hammond, S. M., Bernstein, E., Beach, D. and Hannon, G. J. 2000. An RNA-directed nuclease mediates post-transcriptional gene silencing in Drosophila cells. Nature 404:293-296.

Holsters, M., de Waele, D., Depicker, A., Messens, E., Van Montagu M., and Schell, J. 1978. Transfection and transformation of A. tumefaciens. Mol. Gen. Genet. 163:181-187.

Itaya, A., Folimonov, A., Matsuda, Y., Nelson, R. S., and Ding, B. 2001. Potato spindle tuber viroid as inducer of RNA silencing in infected tomato. Mol. Plant-Microbe Interact. 14:1332-1334.

Jacquemond, M., and Lot, H. 1981. L'ARN satellite du virus de la mosaique du cocombre. I. Comparaison de l'aptitude à induire la nécrose létale de la tomate d'ARN satellites isolés de plusieurs souches du virus. Agronomie 1:927-932.

Jacquemond, M., and Tepfer, M. 1998. Satellite RNA—mediated resistance to plant virus: are ecological risks well assessed? Pages 94-120 in: Plant Virus Disease Control. A. Hadidi, R. H. Khetarpal, and H. Koganezawa, eds. American Phytopathological Society Press, St. Paul, MN.

Jones, L., Hamilton, A. J., Voinnet, O., Thomas, C. L., Maule, A. J., and Baulcombe, D. C. 1999. RNA-DNA interactions and DNA methylation in post-transcriptional gene silencing. Plant Cell 11:2291-2302. 
Kaper, J. M. 1993. Satellite-mediated symptom modulation: an emerging technology for the biological control of viral crop disease. Microb. Releases 2:1-9.

Li, H. W., Lucy, A. P., Guo, H. S., Li, W. X., Ji, L. H., Wong, S. M., and Ding, S. W. 1999. Strong host resistance targeted against a viral suppressor of the plant gene silencing defense mechanism. EMBO (Eur Mol. Biol. Organ.) J. 18:2683-2691.

Lot, H., Marrou, J., Quiot, J. B., and Esvan, C. H. 1972. Contribution à l'étude du virus da la masaique du cocombre (CMV). II. Méthode rapide de purification du virus. Ann. Phytopathol. 4:25-38.

Marathe, R., Anandalakshmi, R., Smith, T. H., Pruss, G. J., and Vance, V. B. 2000. RNA viruses as inducers, suppressors and targets of post-transcriptional gene silencing. Plant Mol. Biol. 43:295-306.

McCormick, S., 1991. Transformation of tomato with Agrobacterium tumefaciens. Pages B6, 1-9 in: Plant Molecular Biology Manual. S. Gelvin and R. Schilperoort, eds. Kluwer Academic Publishers, Dordrecht, the Netherlands.

McGarvey, P. B., and Kaper, J. M. 1991. A simple and rapid method for screening transgenic plants using the PCR. Biotechniques 11:428-432.

Monti, M. M., Valanzuolo, S., Cassani, G., and Colombo, M. 1999. Transgenic tomatoes expressing a cucumber mosaic virus satellite RNA: field testing and analysis of satellite RNA spread. J. Plant Pathol. 81:113-122.

Palauqui, J. C., Elmayan, T., Pollien, J. M., and Vaucheret, H. 1997. Systemic acquired silencing: transgene-specific post-transcriptional silencing is transmitted by grafting from silenced stocks to nonsilenced scions. EMBO (Eur. Mol. Biol. Organ.) J. 16:4738-4745.

Palukaitis, P., Roossinck, M. J., Dietzgen, R. G., and Francki, R. I. B. 1992. Cucumber mosaic virus. Adv. Virus Res. 41:281-348.

Papaefthimiou, I., Hamilton, A., Denti, M., Baulcombe, D., Tsagris, M., and Tabler, M. 2001. Replicating potato spindle tuber viroid RNA is accompanied by short RNA fragments that are characteristic of posttranscriptional gene silencing. Nucleic Acids Res. 29:2395-2400.

Ratcliff, F., Harrison, B. D., and Baulcombe, D. C. 1997. A similarity between viral defense and gene silencing in plants. Science 276:15581560 .

Roossinck, M. J. 2002. Evolutionary history of Cucumber mosaic virus deduced by phylogenetic analyses. J. Virol. 76:3382-3387.

Roossinck, M. J, Bujarski, J., Ding, S. W., Hajimorad, R., Hanada, K. Scott, S., and Tousignant, M. 1999. Family Bromoviridae. Pages 923935 in: Virus Taxonomy. Seventh Report on the International Committee on Taxonomy of Viruses. M. H. V. Van Regermortel, C. M. Fauquet, and D. H. L. Bishop, eds. Academic Press, San Diego, CA.

Roossinck, M. J, Sleat, D., and Palukaitis, P. 1992. Satellite RNAs of plant viruses: structure and biological effects. Microbiol. Rev. 56:265-279.

Ruiz, M. T., Voinnet., O., and Baulcombe, D. C. 1998. Initiation and maintenance of virus-induced gene silencing. Plant Cell 10:937-946.

Sambrook, J., and Russell, D. W. 2001. Molecular Cloning: A Laboratory Manual. Cold Spring Harbor Laboratory Press, Cold Spring Harbor, New York.

Smith, C. R., Tousignant, M. E., Geletka, L. M., and Kaper, J. M. 1992. Competition between cucumber mosaic virus satellite RNAs in tomato seedlings and protoplasts: A model for satellite-mediated control of tomato necrosis. Plant Dis. 76:1270-1274.

Szittya, G., Molnar, A., Silhavy, D., Hornyik, C., and Burgyan, J., 2002. Short defective interfering RNAs of tombusviruses are not targeted but trigger post-transcriptional gene silencing against their helper virus. Plant Cell 14:359-372.

Taliansky, M. E., Ryabov, E. V., and Robinson, D. J. 1998. Two distinct mechanisms of transgenic resistance mediated by Groundnut rosette virus satellite RNA sequences. Mol. Plant-Microbe Interact. 11:367374.

Tien, P., and Wu, G. S. 1991. Satellite RNA for the biocontrol of plant disease. Adv. Virus Res. 39:321-339

Torrance, L. 1992. Serological methods to detect plant viruses: Production and use of monoclonal antibodies. Pages 7-34 in: Techniques for the Rapid Detection of Plant Pathogens. J. M. Duncan and L. Torrance, eds. Blackwell Scientific Publications, Oxford, U.K.

Vance V, and Vaucheret H 2001. RNA silencing in plants-defense and counterdefense. Science 292:2277-2280.

Verwoerd, T. C., Dekker, B. M. M., and Hoekema, A. 1989. A small-scale procedure for the rapid isolation of plant RNAs. Nucleic Acids Res. 17:2362.

Voinnet, O. 2001. RNA silencing as a plant immune system against viruses. Trends Genet. 17:449-459.

Wang, M.-B., Wesley, S. V., Finnegan, E. J., Smith, N. A., and Waterhouse, P. M. 2001. Replicating satellite RNA induces sequencespecific DNA methylation and truncated transcripts in plants. RNA 7:16-28.

Waterhouse, P. M., Wang M.-B., and Finnegan, E. J. 2001. Role of short RNAs in gene silencing. Trends Plant Sci. 6:297-301.

White, J. L., and Kaper, J. M. 1989. A simple method for detection of viral satellite RNAs in small plant tissue sample. J. Virol. Methods 23:83-94.

$\mathrm{Xu}, \mathrm{P}$, Blancaflor, E. B., and Roossinck, M. J., 2003. In spite of induced multiple defense responses, tomato plants infected with Cucumber mosaic virus and D satellite RNA succumb to systemic necrosis. Mol. Plant-Microbe Interact. 16:467-476. 